Article

\title{
A Systematic Approach to Identify Promising New Items for Small to Medium Enterprises: A Case Study
}

\author{
Sukjae Jeong, Jaehyun Han * and Jihyun Kim * \\ School of Business, Kwangwoon University, 26 Kwangwoon-gil (447-1, Wolgye-dong), Nowon-Gu, \\ Seoul 139-701, Korea; sjjeong@kw.ac.kr \\ * Correspondence: jhan@kw.ac.kr (J.H.); jihyunk@kw.ac.kr (J.K.); Tel.: +82-2-940-8264 (J.H.); +82-2-940-8384 (J.K.) \\ Academic Editors: JinHyo Joseph Yun and Marc A. Rosen \\ Received: 27 August 2016; Accepted: 3 November 2016; Published: 10 November 2016
}

\begin{abstract}
Despite the growing importance of identifying new business items for small and medium enterprises (SMEs), most previous studies focus on conglomerates. The paucity of empirical studies has also led to limited real-life applications. Hence, this study proposes a systematic approach to find new business items (NBIs) that help the prospective SMEs develop, evaluate, and select viable business items to survive the competitive environment. The proposed approach comprises two stages: (1) the classification of diversification of SMEs; and (2) the searching and screening of business items. In the first stage, SMEs are allocated to five groups, based on their internal technological competency and external market conditions. In the second stage, based on the types of SMEs identified in the first stage, a set of alternative business items is derived by combining the results of portfolio analysis and benchmarking analysis. After deriving new business items, a market and technology-driven matrix analysis is utilized to screen suitable business items, and the Bruce Merrifield-Ohe (BMO) method is used to categorize and identify prospective items based on market attractiveness and internal capability. To illustrate the applicability of the proposed approach, a case study is presented.
\end{abstract}

Keywords: identification of promising ideas; SMEs; benchmarking analysis; Bruce Merrifield-Ohe (BMO)

\section{Introduction}

The majority of small and medium enterprises (SMEs) in Korea seem to be aware that their business does not operate in a very promising field; however, they show little capacity to plan ahead. The products developed by SMEs are often short-lived and imitated by other competitors [1], making SMEs pessimistic about their future.

According to a survey by the Korean Small and Medium Business Administration (2013) [2], $85.8 \%$ of total revenues comes from core products and $37.3 \%$ of all SMEs that participated in the survey responded they have no growth potential in the field. Additionally, $48.6 \%$ of all respondents said they have no new growth engines to sustain their business.

As the demand for new promising business items has increased, many domestic and international organizations have suggested and applied models or processes for identifying new promising business items.

Many models can only be applied to conglomerates and are not suitable for SMEs. Since the process of identifying new promising business items requires large resources and is often time consuming, most SMEs cannot afford it. This contributes to the differentiated characteristics between SMEs and conglomerates.

Generally, SMEs suffer to sustain their business when the life span of their core product is in mature stage or they do not have competitive edge in their market regardless of a particular sector in industry or their size. Among them, innovative SMEs, to overcome such challenges, invest in R\&D aggressively in order to develop new products or diversify existing core products and to develop or 
diversify a firm's technology or products, if they have enough capital and human resources. If not, they try to find external help like government supporting programs to implement their new promising business item. There exist many government sponsored programs to help improve SMEs' information or tools (databases) relevant to market and industrial trends to support SMEs' sustainable business, as well as setting up SMEs with experts in the area of HR, finance, market and technology almost free of charge. In Korea, the "Technological Innovation Development Program" by Small and Medium Business Administration is one of the examples [3].

Meanwhile, conglomerates refer to a group (or groups) of companies and possess various core products that are produced by advanced technology in their industry, by their divisions. Although core products of a certain division have become mature, conglomerates can generally tunnel their financial and human resources among groups or divisions. By helping each other out within a group (or groups), they can have enough resources to develop new product and technology by themselves.

Given that existing processes or models for identifying new promising business items are designed for firms, regardless of their capabilities, developing a model specifically targeting SMEs is of key importance. Thus, this study proposes a process for identifying new promising items specifically targeting SMEs and identifies application processes that can cover various types of SMEs, based on different kinds of diversification strategies. First, this study proposes a conceptual framework to identify new business items for SMEs. Second, it also shows the detailed process of identifying new business items for SMEs with a case study. The remainder of this paper is organized as follows. Section 2 discusses the research background. Section 3 describes the proposed model and general process to implement it. Section 4 presents how to approach the process by diversification types of SMEs, and the case study using our proposed process is demonstrated in Section 5. Section 6 concludes the paper.

\section{Research Background}

According to Jun et al. [4], diversification strategies (direction) and processes (roadmaps) are required to SMEs for searching new business.

We review literatures based on two perspectives, namely, diversification strategy and diversification process. Diversification is an effective way for firms to identify new promising business items. Many existing models and processes for identifying new business items are based on the concept of diversification. Thus, it is important to recall the definition of diversification and discuss various types of diversification.

Diversification refers to business activities that increase diversity by expanding products or markets [5]. When core products are matured and growth potential reaches its limit, a firm starts to consider diversification. But, the choice of diversification strategy can vary among firms. Generally, existing studies divided diversification into related and unrelated diversification. When a firm believes that core technology of its products has an edge over competitors, it chooses to diversify its products by modifying its core technology and thus develop substitutable products within the value chain of the core product. This strategy is referred to as related diversification [6,7]. According to Anil and Yiğit [7], related diversification expands the existing products and markets within a sector. A firm's related diversification, generally, is a strategic choice taken when a firm's core competency has a competitive edge and there is an anticipated synergy effect. In the field of strategic management, related diversification is mainly discussed in terms of a resource-based view, or "core competency" [8]. The potential benefit of related diversification is an operation synergy effect obtained through shared resources and by transferring technologies among divisions for specific functions or competitive products [9].

On the other hand, when its core technology is not unique in the market and is caught up with competitors, a firm chooses to develop a new technology and thus pioneers into a new market. This is called as unrelated diversification. 
The main goal of unrelated diversification is to reduce the risk of external capital markets by effectively using internal capital through competition among divisions [10]. The potential benefit relates to financial synergy rather than operational synergy, and implies sharing financial and general management resources. Table 1 summarizes the differences between related and unrelated diversification.

Table 1. Related vs. Unrelated diversification.

\begin{tabular}{ccc}
\hline Criteria & Related Diversification & Unrelated Diversification \\
\hline Basic Characteristics & $\begin{array}{c}\text { Diversification related to existing business } \\
\text { (similar market in terms of marketing, } \\
\text { distribution, production technology) }\end{array}$ & $\begin{array}{c}\text { Diversification into new business } \\
\text { unrelated to existing business }\end{array}$ \\
\hline Method & $\begin{array}{c}\text { Use of existing brand name, resources, } \\
\text { technology, marketing ability, etc. }\end{array}$ & M\&A and /or R\&D \\
\hline Transferable Resources & $\begin{array}{c}\text { Operational skill, distribution system, } \\
\text { production resource, etc. }\end{array}$ & $\begin{array}{c}\text { General management skills, } \\
\text { capital resources }\end{array}$ \\
\hline $\begin{array}{c}\text { Expected Result } \\
\text { (Object) }\end{array}$ & $\begin{array}{c}\text { Economy of scale, specialty, synergy, } \\
\text { operational efficiency, market power, stable } \\
\text { revenues and profits }\end{array}$ & $\begin{array}{c}\text { Risk reduction, growth opportunity, } \\
\text { cost reduction, efficient capital and } \\
\text { resource management, lower cost of } \\
\text { capital, stable revenues and profits }\end{array}$ \\
\hline $\begin{array}{c}\text { Possibility of Earning } \\
\text { Potential Profit }\end{array}$ & $\begin{array}{c}\text { Difficulty of integrating the new business into } \\
\text { an existing business; thus, more difficult }\end{array}$ & $\begin{array}{c}\text { Relatively easier due to no issues of } \\
\text { integration and control }\end{array}$ \\
\hline
\end{tabular}

Once a firm chooses between the two diversification types, it examines processes to implement developing promising business items.

Most diversification studies have focused on the definition and types of diversification, and on the relationship between diversification and firm performance. Only a handful of studies have focused on how to implement the diversification strategy in practice.

The typical process of searching for new business items consists of three stages, namely, list-up (or identification) of promising items, screening, evaluation [11,12].

In the identification stage, promising new business items are listed up based on analysis of internal capability, analysis of industrial trend, and benchmarking [13,14]. In screening process, market size, growth potential, and technology accessibility among others are prioritized. Through a communication with the requesting firms, only a handful of items are selected. The final and evaluation stage determines whether the candidates have enough market attractiveness and internal capability [15].

Recently, a few large consulting firms have developed and applied their own process based on such an implementation method.

We review the processes used by some firms. Figure 1 shows the process for identifying new promising business items of the LG Economic Institute. It can be split in two steps: a boundary-less search and evaluation/filtering. The former is a step to identify new promising ideas and has four approaches, namely, the demand-pull approach, the tech-push approach, the industry dynamics approach, and the benchmarking of internationally successful business. The latter goes through first screening to fourth screening to get final ideas by evaluating their feasibility, possibility of large business, empirical and intuitive assessment, and analysis of the business overall feasibility.

OpenTide Korea, generally, starts with an identification process by defining the new business areas shown in Figure 2. After defining such areas, an iterating process of searching and evaluating new business candidates follows. Last, a strategy of commercialization and an action plan for commercialization are discussed. The identification process of OpenTide Korea considers three approaches: first, an "inside-out approach" to identify the candidates in terms of new distribution network, customer, product, and enhancement of the value chain, when the firm holds a core capability in an industrial leader group. 


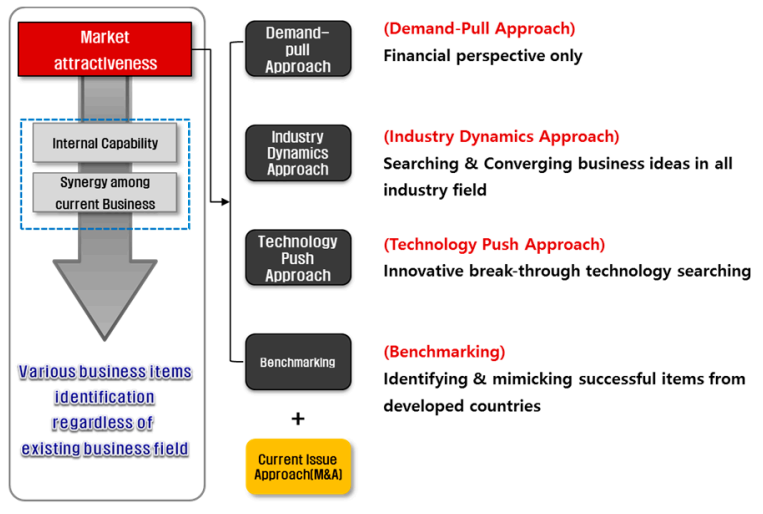

Figure 1. Identification Process of the LG Economic Institute (from internal source).

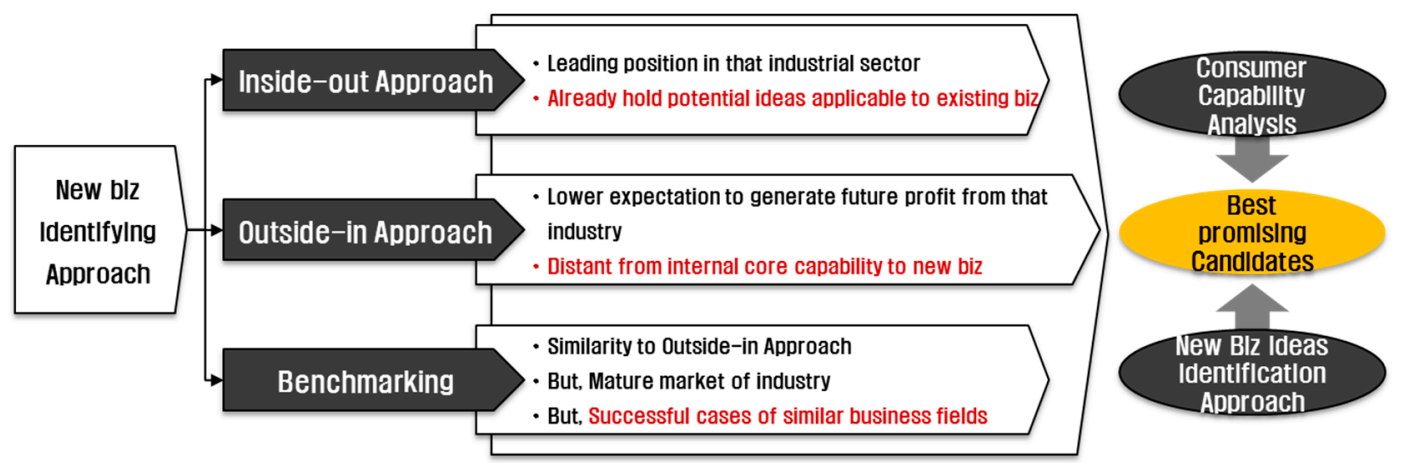

Figure 2. Identification Process of the OpenTide Korea (from internal source).

Second, an "outside-in approach" identifies the promising business items through an intermediate and long-term trend analysis, when the expectation to generate future profits from that industry is low. Last, "benchmarking" is an approach to identifying new business items through the analysis of the business portfolio of the leading company in a certain field and addressing the success factors of the business diversification of the leading company.

The SBP Strategic Management Institute divides firms into two groups. The first group comprises firms that want to obtain core competencies based on the analysis of changing direction elements of future business environments. The second group comprises firms that want to develop new business/new products based on their core competencies. The process has six steps, as shown in Figure 3.

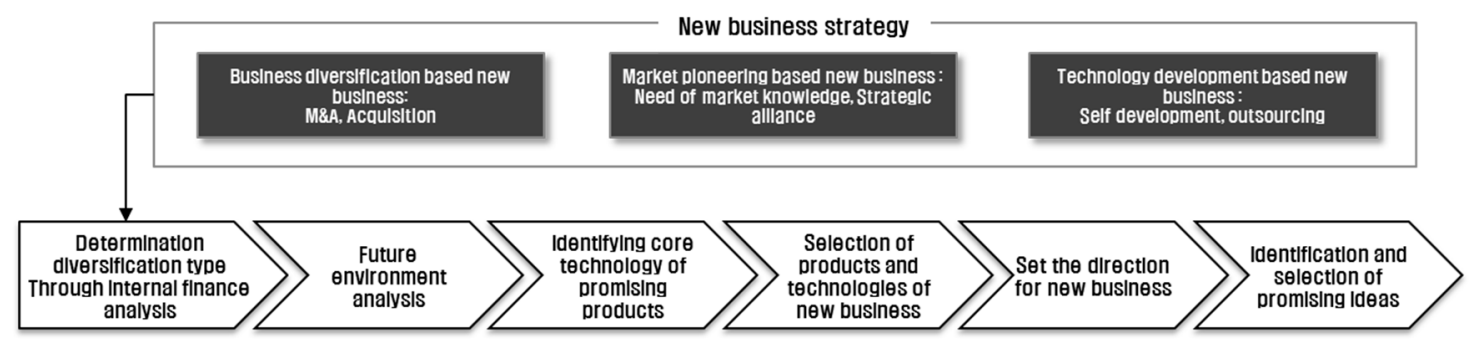

Figure 3. Identification process of the SBP Strategic Management Institute (from internal source).

The first step of this model is an internal financial analysis. In this step, the institute reviews whether either existing business concentration or new business development prevails. The second step is the analysis of the future business environment. It is a comprehensive analysis of the changing direction of a business and business items. The third step is to identify products and technology opportunities. 
It is the materialization of the technology required by a new business. The fourth step is to select products and technology for the new business. It ranks items and technologies based on their internal capability and market attractiveness. The fifth step is to set directions for the new business. It identifies the direction of promising items, based on technology and market comprehension of the company. The last step is to identify and select promising ideas through a focused group interview (FGI).

The identification process of Frost and Sullivan has six steps, similarly to that of the SBP Strategic Management Institute, as shown in Figure 4. The first step is to understand customers' needs, and in which directions they want to go. After an interview with customers, they target the business following customers' requirements and identify a number of benchmarking companies. After analyzing products and business portfolios of benchmarking companies, they perform feasibility tests on business products and technologies absorbed from benchmarking companies, and try to forecast the future of those products and technologies. After the feasibility test, they compare and evaluate all business items. Finally, they choose and present the best items and their future trend.

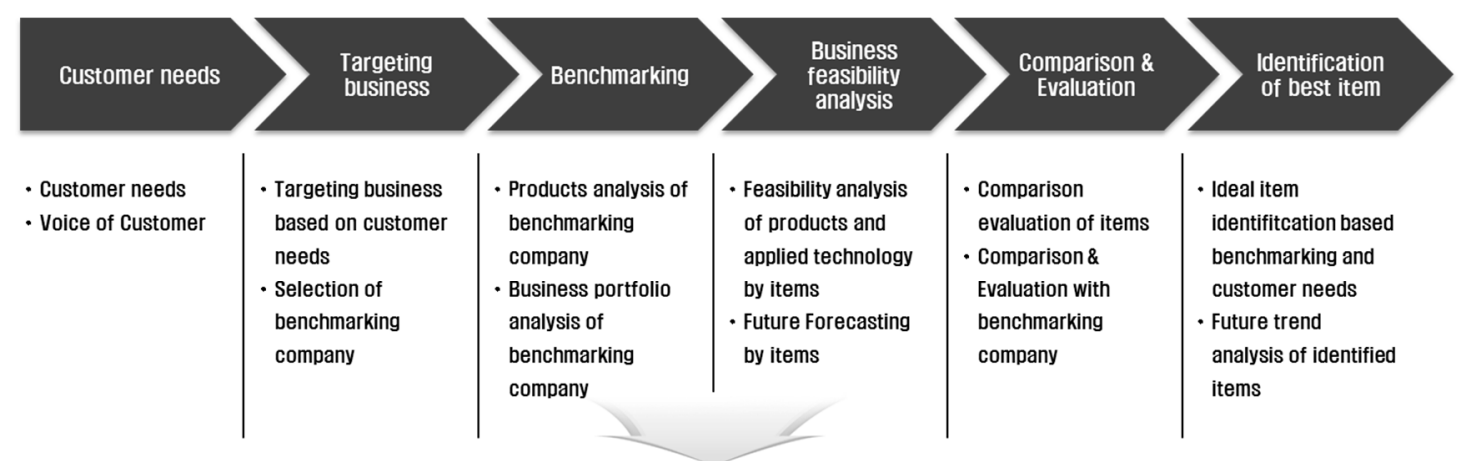

Identification Promising item

Figure 4. Identification process of Frost and Sullivan (from internal source).

Unlike a few processes for big firms, there are little a general process targeting SMEs. Jun et al. [4] introduced one exception, a case of SMEs in UK using the Cambridge T-Plan approach for generating their core products and technologies.

SMEs are more important today than in the past, due to their capabilities of creating new markets and boosting the relevant industry. SMEs need continual innovation to survive in a competitive market and to continue growth. But SMEs suffer from the lack of information to generate innovative ideas.

Hence, the objectives of this study are to suggest a new tool to recommend promising idea to SMEs that need "knowledge arbitrage" and to help SMEs come up with ideas on new markets.

\section{The Proposed Model for Identifying New Business Items for SMEs}

Such examples are mostly cases of business items identification process prepared by large scale corporations; by contrast, there are not many examples of SMEs that have self-implemented the roadmaps for the small company unit.

Based on the theoretical framework discussed above and the new items identification processes utilized by various consulting firms, we propose a new model for identifying new business items, specifically designed for SMEs, as shown in Figure 5.

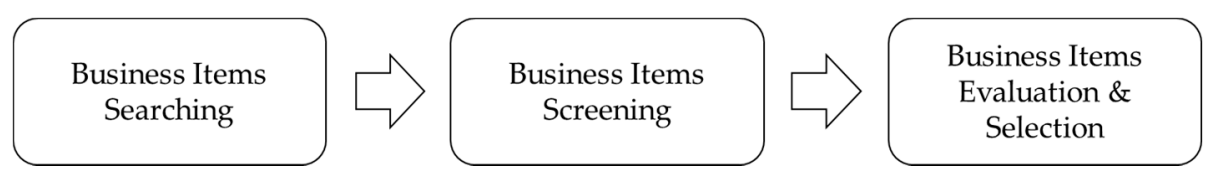

Figure 5. Identification model of new business items for SMEs'. 
First, various business items are identified, based on market trends of associated industries, related benchmarking companies, and on their competitiveness. This step is called "items searching". Next, focus groups of experts from both within and outside the company are interviewed to filter candidate groups of business items, based on the relevancy to the company and its future prospects. This step is called "items screening". Last, a Bruce Merrifield-Ohe (BMO) is performed on the candidate groups to evaluate the market prospects and compatibility with the company, and the promising items are finally selected. The BMO method is suitable for selecting a business out of many candidates. It screens business items by asking the following questions sequentially: (1) Is the business attractive enough? (2) If so, does the business item fit the firm? (3) If the business is both attractive and fits the firm, how high will the success rate be? Although the BMO tends to be objective and has an organized framework consisting of market attract attractive and internal capacity [16]. This step is called "business items evaluation and selection."

The generalized process can be broadly divided into two steps: the identification and the evaluation process. The detail of each step is described as follows.

The searching process of promising business items is divided into identification of promising business items and evaluation and selection of the derived items. The first step relates to the internal capability of analysis of the firm and includes a management capability analysis and business portfolio analysis within the firm. To target the industrial sectors of interest, the firm performs a market and technology trend analysis of the target industry. Additionally, this step lists the emerging business items of a requesting firm through a benchmarking analysis targeting similar international firms that examine new business sectors, their sales and R\&D analyses, and their main business portfolio sectors. In the evaluation and selection stage, we select the final promising business items from all ideas listed in the previous stage conducting a technology and market analysis, a screening procedure for evaluating the promising ideas, and an in-depth analysis of the business value of such ideas. The detailed steps for identifying promising business items are as shown in Figure 6.

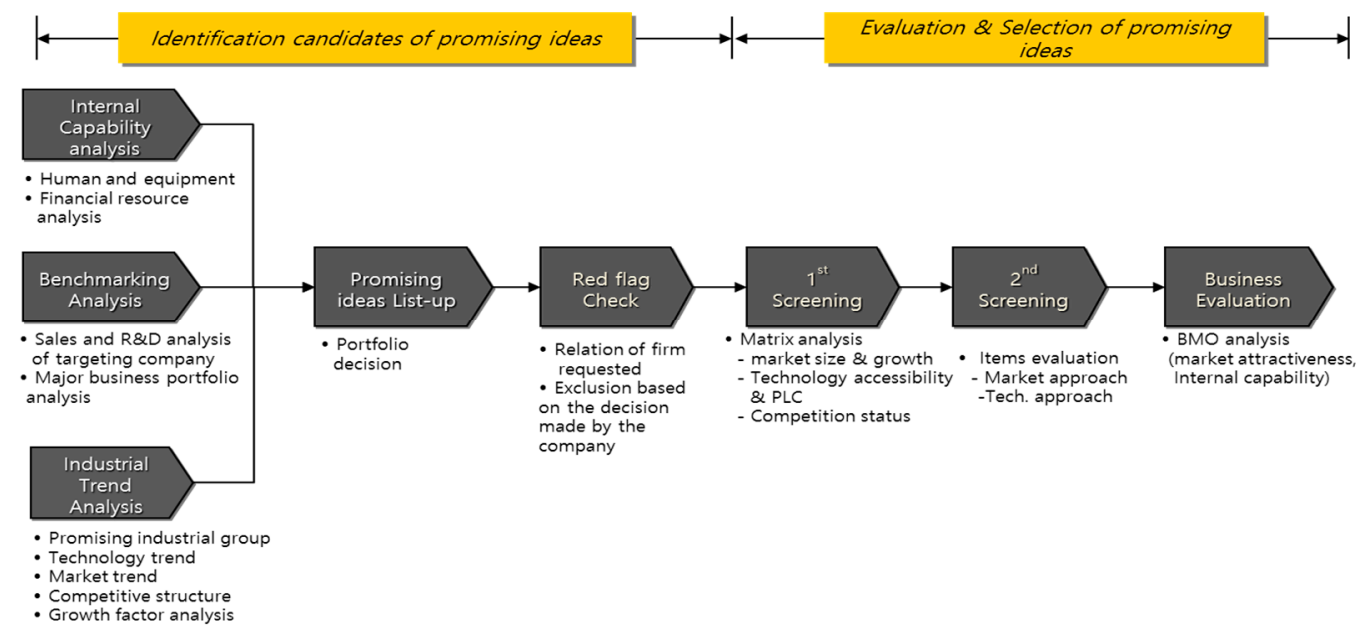

Figure 6. Generalized identification process.

Step 1. Firm's Internal Capability Analysis

The capability analysis derives the key success factors in each business sector through an analysis of a firm's internal capability and strengths, and competitive advantages. To that end, we analyze a firm in terms of four aspects: customers, human resources, business, and performance perspectives.

Step 2. Industrial Trend Analysis

Based on the industrial sectors of interest, an industrial trend analysis is performed. The trend analysis considers an overview of the target industry, recent trends and characteristics, the future 
demand for technology related with each industry, the formal market, and technology trends. In addition, this step provides the ground for alternative promising business items by comparison with a few domestic and international competing companies.

Step 3. Benchmarking with Similar Foreign Companies

Targeting similar companies within industry sectors of interests, the benchmarking analysis is carried on by examining the business diversification, key success factors, current business status, and future business plan and direction of similar firms, as well as their business segments and R\&D status, and portfolio analysis of their major business sector.

Step 4. Listing Promising Business Items

In the step of internal capacity analysis, promising ideas are identified, based on insights and key success factors through an internal analysis of firms, considering factors such as existing customers' status, market environment and size of related sectors, human resources and fulfillment results of R\&D, financial performance, intellectual property rights, market share by business sectors, as well as the firm's internal interests. Then, through an industry trend analysis, promising ideas are identified based on the grounds for business items derived from the industry trend analysis and from the perspective of professionals. In the benchmarking analysis step, ideas are listed based on successful business items of similar companies, through business diversification. The ideas derived from such steps are then communicated to the requesting firm.

The detailed steps for the evaluation and selection of promising ideas are as follows: the best ideas are selected among all business items derived from the previous steps through an evaluation procedures comprising a first and second screening, and a BMO analysis.

\section{Step 5. First Screening}

Ideas are prioritized through a matrix analysis of the market size and growth potential, technology accessibility and technology development cycle, and domestic and international competition. The results are communicated to the requesting firm and a few ideas are selected through an internal review process.

\section{Step 6. Second Screening}

In this stage, the technical requirements, application areas, related market trend and growth cycle, recent trends of related companies, future perspectives of related products, and R\&D development of each of the selected ideas are analyzed. Based on the quantitative evaluation and matrix analysis of the technology-push and demand-pull based on such results, only a few business items are selected.

\section{Step 7. In-Depth Analysis of the Business Potential}

The ideas selected through the second screening are evaluated in terms of market attractiveness and the firm's internal capability through a BMO analysis. Market attractiveness screens a business out of many candidate ideas by asking the question "Is the business attractive enough?" and evaluates the following factors: market size, market growth rate, risk aversion, degree of competition, creation of a new market, uncertainty in demand pull, and trend of change in the external environment. On the other hand, the firm's internal capability measures how successful a firm is in an industry by evaluating the following factors: fund responsiveness, market ability, manufacturing and operational ability, possession of fundamental technology, customer service ability, the capacity to secure information for existing companies from up-stream to down-stream, and the management support ability. Through a scoring process, the BMO method classifies withdrawal, conditional, and prospective business areas.

The biggest issue of the generalized process we have discussed so far is that it requires a large number of resources, which a typical SME cannot afford. However, given the current fast-changing and competitive nature of business environments, effective time management is an important factor for 
success. In the generalized process, the first step of identification is rather time consuming. Given that testing and implementing new promising business items need additional time, applying the whole complex process is not always the best answer. Most SMEs do not need detailed information on various business fields and ideas. They mostly need to know how their existing market and technology can be applied into new fields and markets because they typically do not have enough resources for promising fields (capital and human resources, in addition to time).

\section{Classification by Diversification Types of SMEs and Their Flexible Processes}

\subsection{Classification of SMEs Based on Market and Technology Diversification}

Using a market and technology matrix, the business diversification types of SMEs are divided into five classes and based on types of diversification as shown in Figure 7.

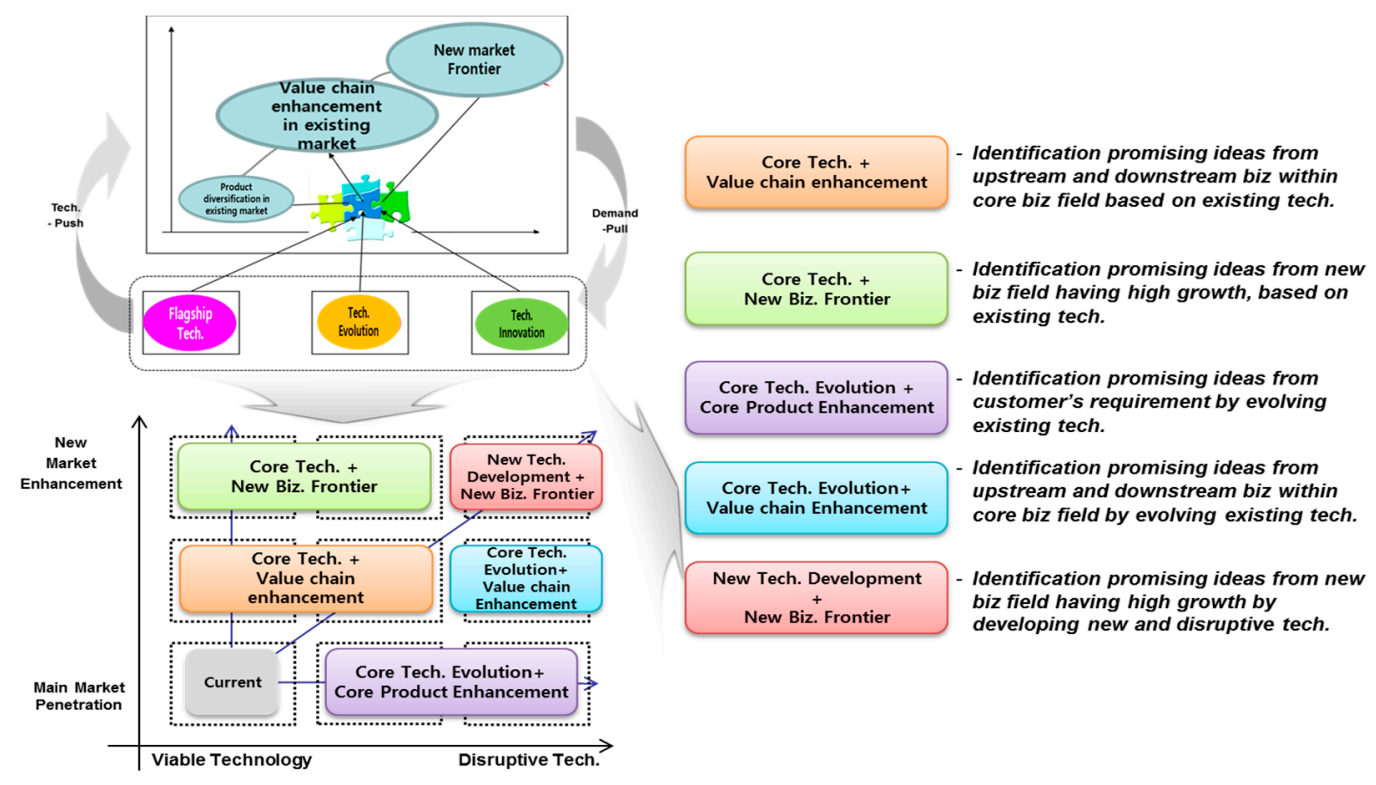

Figure 7. Business diversification based on SMEs' characteristics.

The first class of SMEs has global level technologies, but lacks the ability to successfully enter new markets or to market products. These companies seek to create new business fields to expand the market, based on the technologies that they currently possess. This class of SMEs is labeled "core tech. + value chain enhancement". These companies pursue new business items that will broaden their market using the application and expansion of current product/group of products.

In the second class, if a company is faced with market saturation, it seeks to cultivate a new market using its core technologies. This class of SMEs is named "core tech. + new biz. frontier".

SMEs with insufficient funds to invest in $R \& D$ will evaluate both the attractiveness and prospects of the market. If it is concluded that there still exists abundant possibility of market expansion, companies would try to increase their market share by enhancing their core technologies. These companies are classified as "core tech. evolution + core product enhancement". If the market is overly saturated, companies seek a new business that will expand their current business by evolving their core technologies. These companies are labeled as "core tech. evolution + value chain enhancement".

If a firm possesses a sufficiently large market share, shows a good competitiveness in a saturated market, and retains enough funds to invest in $R \& D$, it develops a new technology and cultivates new markets. This type of firm is classified as "new tech. development + new biz. frontier". In order to identify the class of each SME, the analysis of the internal resources of each company needs to be 
performed by business professionals, using a checklist of technology resources, financial resources, resources related to the market environment, and other related resources.

\subsection{Flexible Processes of Diversification Types of SMEs}

In this section, based on the five cases that we identified, we present a simplified and customized process by comparing it with the general process in Section 3.

\subsubsection{Customized Process of "Core Tech. + Value Chain Enhancement"}

SMEs with the type of "core tech. + value chain enhancement" diversification need information of value chain enhancement and possibility of business expansion through benchmarking. Compared to generalized processes, we exclude industrial trend analysis since SMEs just want to expand their technology and markets, which implies that they do not have to waste time in searching for new promising fields. We also simplified the process of ideas screening by excluding red flag check step because, in the BMO analysis, it can be evaluated by internal capabilities. Also, by using experts' FGI, we simplified the first and second screening.

\subsubsection{Customized Process of "Core Tech. + New Biz. Frontier"}

SMEs with the type of "core tech. + new biz. frontier" diversification need information of future trends of promising fields for entering into a new market as well as applicability of core technology and capabilities of the firm. But, by excluding the step of internal capability analysis, we simplify the ideas searching process. In the red flag check (RFC) step, firms typically exclude candidates based on familiarity with them. For entering into a new market, it is important to notice other promising field other than their own business market. In the stage of screening, we just do the first screening by experts' FGI. Finally BMO analysis is conducted.

\subsubsection{Customized Process of "Core Tech. Evolution + Core Product Enhancement"}

SMEs with the type of "core tech. evolution + core product enhancement" need information of future trends of promising fields and demand of customers and product diversification of leading companies through benchmarking. This case is to present differentiated products which satisfy existing customers' needs. Thus, by excluding analysis of internal capabilities, we simplified the ideas searching stage. Also, in the screening stage, it is important to note the insights of top management of the firm who understand their own business well. Thus, there is no need for experts' opinions. By skipping the first and second screening, we simplify the process. Instead, by doing technology based RFC and clustering similar ideas, we evaluate candidates.

\subsubsection{Customized Process of "Core Tech. Evolution + Value Chain Enhancement"}

SMEs with the type of "core tech. evolution + value chain enhancement" need information of the chain of the core business, applicability of existing technology, and market expansion through benchmarking. Compared to generalized process, we simplified the searching process by excluding industrial trend analysis. In the screening stage, we also excluded the second screening because, in this case of diversification, it is not for developing new technology or entering into a new market. Thus, by doing RFC based on technology and market and clustering ideas, we first screen the candidate then proceed with experts' FGI.

\subsubsection{Customized Process of "New Tech. Development + New Biz. Frontier"}

SMEs with type of "new tech. development + new biz. frontier" need all information regarding the generalized process, since it is completely new to the firm in terms of technology and market. But, there is a difference in the screening stage. Unlike the generalized process, we exclude RFC preventing the firm excluding new business items unfamiliar with their own business. Even though 
we exclude RFC, by doing expert's FGI for the first and second screening internal managements' FGI, we minimize risks of missing important candidates.

\section{Case Study}

This case study is an extension of the project "Development of identifying new promising items for the SMEs" in 2013 conducted by the authors [17]. Our work included introduction of our process to a target firm, interview of the firm's directors, a focus group interview, and implementation of our process and lasted approximately three months. The data, which were obtained in "Company A" for project, were employed to analyze each steps with our proposed process in Section 4 . In order to examine the internal capability of "Company A", the authors gathered primary data directly from "Company A" and conducted a FGI, which employed BMO analysis. The FGI was conducted for two weeks by means of telephone and e-mail. The authors conducted CEOs or advisors, but some of them accepted the interview requests. The FGI was conducted with them engaging in relevant industry and venture capital.

Since it was founded in 1973, Company " $\mathrm{A}$ " has specialized in manufacturing fine chemicals for the automobile industry. Their core product represents approximately $55 \%$ of domestic market share of Korea. The recognition of the high quality of the company's automobile product led to monopolizing the export automobile market and to a domination of over $80 \%$ of domestic market share.

However, market saturation of the company's main products necessitates new business promotion strategies and plans to attain further growth.

From the area of manufacturing fine chemicals for the automobiles, the company is seeking to extend the product line to automobile related products, and to expand to other fields, such as semiconductors, ships, and environment.

Before proceeding with the process of identifying new business items, an analysis of the internal capability of the firm was performed using a checklist. The analysis results showed that the company belongs to the "core tech. + new biz. frontier" class.

A trend analysis of the automobile, shipbuilding, and semiconductor manufacturing industry was performed by request from Company " $\mathrm{A}$ ". In the case of automobile and shipbuilding industries, increased safety demands, performance enhancement, and environmental awareness were identified as key market growth factors. Based on the results of the analysis, five new business items, including wet dual clutch transmission (DCT) oil, were identified.

In the case of semiconductor manufacturing, the trend analysis revealed that localizing and securing source technologies, increasing the utilization of existing chemicals, and creating new chemicals to satisfy the increasing demand for microfabrication and fulfilling environmental responsibilities were the key future growth factors. Using these findings, seven new business items, including the atomic layer deposition (ALD) precursor, were selected.

For searching for other business items, a benchmarking analysis was also performed. By recommendation of external experts, Company " $\mathrm{B}$ " was chosen as the benchmark. Company " $\mathrm{B}$ " was founded in 1994 and its major products are reagents and electronic chemicals. In 2012, total sales amounted to approximately 0.39 billion dollars. The company benchmarked is seeking diversification by expanding its business through etchants and resist removers. Through benchmarking, eight items such as alpha-olefin, Electromagnetic interference (EMI) Shielding, and deicing fluid etc., were identified as new promising items. As shown in Table 2, a total of 20 new business items from industrial trend analysis and from benchmarking analysis were recognized as possible new items. 
Table 2. List-up of business items recommended in identification stage.

\begin{tabular}{|c|c|c|}
\hline \multicolumn{2}{|c|}{ Industrial Trend Analysis (12) } & \multirow{2}{*}{ Benchmark Analysis (8) } \\
\hline Automobile and Shipbuilding (5) & Semiconductor (7) & \\
\hline $\begin{array}{l}\text { Wet DCT oil } \\
\text { Hydraulic Auto Tensioner inside } \\
\text { Special Oil } \\
\text { Phenolic Resin Accessory } \\
\text { Idler Pulley } \\
\text { Urea } \\
\text { Ammonia Sensor for urea-selective } \\
\text { catalytic reduction (UREA-SCR) }\end{array}$ & $\begin{array}{ll}\text { Photoresist for extreme } \\
\text { ultraviolet (EUV) } \\
\text { Precursor for ALD } \\
\text { Tetramethylammonium } \\
\text { hydroxide (TMAH) Developer } \\
\text { Coating Film of Low } \\
\text { Dielectric Constant } \\
\text { Cu Plating Solution } \\
\text { Cu Film chemical mechanical } \\
\text { polishing (CMP) Slurry } \\
\text { Stripper }\end{array}$ & $\begin{array}{ll}. & \text { Alpha-Olefin } \\
. & \text { EMI Shielding } \\
. & \text { Alginic Acid } \\
. & \text { Urban Mining } \\
\cdot & \text { Deicing Fluid } \\
. & \text { Equamide } \\
\cdot & \text { Eco-Friendly } \\
& \text { Deicing Chemicals } \\
\text { Heat-Medium Oil }\end{array}$ \\
\hline
\end{tabular}

The market feasibility and technology accessibility analysis were performed in screening stage. Firstly, focus group interview by marketing experts was performed for market feasibility analysis by each of 20 listed items. Those with one or more negative reviews for both criteria (the future market size and CAGR) were screened out. Out of 20, 11 business items passed the screening step in Table 3.

Table 3. Candidates of business item filtered in market feasibility analysis of screening stage.

\begin{tabular}{lll}
\hline \multicolumn{2}{c}{ Industrial Trend Analysis (6) } & \multirow{2}{*}{ Benchmark Analysis (5) } \\
\cline { 1 - 2 } Automobile and Shipbuilding (2) & \multicolumn{1}{c}{ Semiconductors (4) } & \\
\cline { 1 - 2 } & Photoresist for EUV & EMI Shielding \\
Urea & Precursor for ALD & Alginic Acid \\
Ammonia Sensor for UREA-SCR & Coating Film of Low Dielectric Constant & Urban Mining \\
& Cu Plating Solution & Eco-Friendly Deicing Chemicals \\
& & Heat- Medium Oil \\
\hline
\end{tabular}

For the 11 business items that passed the market feasibility analysis, a technology accessibility analysis was also performed. A group interview of industry experts was conducted to evaluate the technology accessibility for Company "A", as well as its technology life cycle. Only four items received a positive review for both criteria. The business items that passed the technology accessibility analysis are shown in Table 4.

Table 4. Candidates of business item filtered in technology accessibility analysis of screening stage.

\begin{tabular}{cc}
\hline Industrial Trend Analysis (1) & Benchmark Analysis (3) \\
\hline Urea & Urban Mining \\
& Eco-friendly deicing chemicals \\
Heat-Medium Oil
\end{tabular}

Finally, to estimate future business prospects, the BMO analysis is applied to the four business items, considering the factors of market attractiveness and internal competency reported in Table 5. 
Table 5. Factors considered by the BMO method.

\begin{tabular}{|c|c|}
\hline BMO Analysis & Factors \\
\hline $\begin{array}{l}\text { Market attractiveness } \\
\text { (Is the market attractive enough?) }\end{array}$ & $\begin{array}{l}\text { Factor } 1 \text {. Profitability } \\
\text { Considers ROI and future ( } 5 \text { years) market size } \\
\text { Factor } 2 \text {. Growth prospect } \\
\text { Considers average growth rate of the market for five years after } \\
\text { market entry ( } 20 \% \text { to } 5 \%) \\
\text { Factor } 3 \text {. Degree of competition } \\
\text { Competition in the industry and related ones (product/service life } \\
\text { cycle, patents \& trademarks, Number of competitors) } \\
\text { Factor } 4 \text {. Diversification of risk } \\
\text { Number of market segmentations } \\
\text { Factor } 5 \text {. Possibility of industry restructuring } \\
\text { Innovativeness of technology and products/services } \\
\text { (innovative products and sales) } \\
\text { Factor } 6 . \text { Relevant external environment } \\
\text { Regulations \& constraints including legal, ethical, political, } \\
\text { environmental, and fair competition }\end{array}$ \\
\hline $\begin{array}{l}\text { Internal competency } \\
\text { (Does the business fit the firm?) }\end{array}$ & $\begin{array}{l}\text { Factor } 1 \text {. Financing } \\
\text { Investment size \& financing } \\
\text { Factor } 2 \text {. Marketing } \\
\text { Is market entry possible with existing marketing methods? } \\
\text { Factor 3. Manufacturing \& operation } \\
\text { Flexibility of facilities, manpower, knowledge, and equipment } \\
\text { Factor } 4 \text {. Technology \& customer service } \\
\text { Technology \& planning capabilities } \\
\text { Factor 5. Input/component/information } \\
\text { Input, component, procurement capabilities, information } \\
\text { Factor } 6 . \text { Management support } \\
\text { Management support on the business }\end{array}$ \\
\hline
\end{tabular}

Both the marketing experts for market feasibility analysis and industry experts for the technology accessibility analysis participated in the BMO analysis. As shown in Figure 8, the analysis results showed that urea, eco-friendly deicing chemicals and heating medium oil belong to the "promising business group", and urban mining belongs to the "conditional promising group".

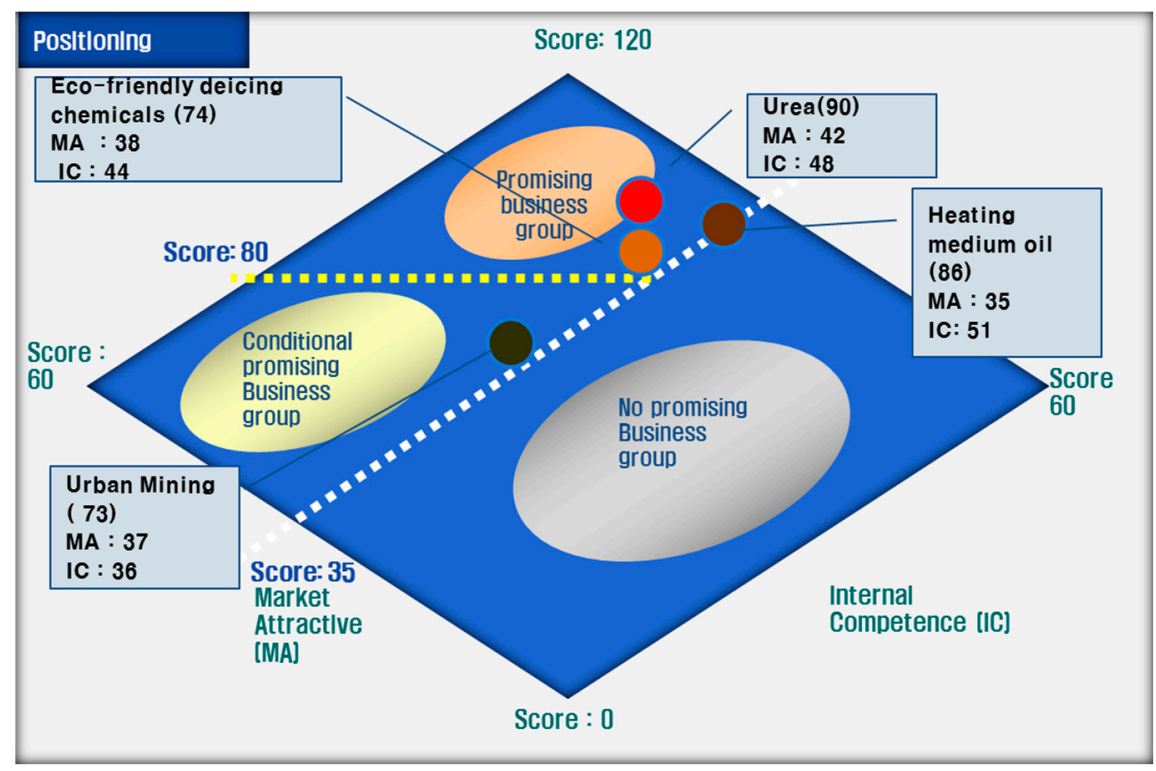

Figure 8. The result of the BMO test. 
In case of eco-friendly deicing chemicals, one of those deduced from the BMO analysis in the final steps of our model has been commercialized since 2014. For implementation of new business, they invested 100 thousand USD and reach sales of 440 thousand USD.

In case of urea, they have finished technological development. In order to manufacture, they build the factory with size of about $1500 \mathrm{~m}^{2}$ in Eonyang-eup, Ulju-gun, Ulsan, Korea and they expect the commercialize in near future.

\section{Conclusions and Discussion}

This study presents a process of identifying new promising ideas for SMEs, based on several types of diversification of SMEs. We emphasize that existing studies on diversification and processes are difficult to apply to SMEs, even though they would be extremely useful. To compare our process with existing processes, we review the identification process used by other studies and practical applications on diversification, and we identify some common factors among processes and generalize them.

We firstly propose a general process and the detailed procedure by each step to identify new business items for SMEs. For a practical application of the general process, we classify five types of SMEs according to diversification strategies and demonstrate how to make a general process flexible and customized by diversification type of the SMEs.

The contribution of our research can be summarized as follows: (1) Faced with competitive and fast-changing business environments, SMEs are in dire need of new technology and products to sustain their businesses. This is critical especially for SMEs whose core products are mature or in a declining industry. By differentiating and ramifying diversification types for SMEs, SMEs can choose a diversification strategy fit to their needs; (2) This study provides how SMEs, which have declining core products, can survive in their competitive market. For that, we recommend and present marketable items that are the fitness of a given firm's internal capability and external market conditions. Unlike previous models, which have applied the identical process uniformly regardless of the firm's internal capabilities and market conditions, the proposed model applies unique processes reflecting the characteristics of SMEs. As soon as SMEs identify their strategy (type), the process can be implemented. By providing the simplified and customized process of identifying new business items, SMEs, with limited internal (within a firm) and external resources, can have access to the process of identifying promising business items required to sustain their businesses for their future.

Our proposed process has been applied through various types of SME and has been continuously modified through the feedback of application results. The case study presented in Section 5 is one example. In order to raise the success rate of the model, the creation of many references are needed by testing our model with various SMEs. The validity of the model should be examined by accumulating more data, which will be used as materials of our future research.

Acknowledgments: This work was supported by the Ministry of Education of Republic of Korea and the National Research Foundation of Korea (NRF-2016R1C1B1016054). The present research has been conducted by the Research Grant of Kwangwoon University in 2015.

Author Contributions: Jaehyun Han and Sukjae Jeong conceived and generated research idea; Jaehyun Han and Jihyun Kim analyzed the existing processes; Sukjae Jeong and Jaehyun Han developed the new process; Jihyun Kim and Sukjae Jeong presented a case study; Jihyun Kim wrote the paper.

Conflicts of Interest: The authors declare no conflict of interest.

\section{References}

1. Yun, J.J.; Won, D.; Park, K. Dynamics from open innovation to evolutionary change. J. Open Innov. Technol. Market Complex. 2016, 2, 1-22. [CrossRef]

2. Survey on Actual State of SMEs. Available online: http:/ /stat2.smba.go.kr/downProc.jsp?seq=2907 (accessed on 11 October 2016).

3. Small and Medium Business Administration of Korea. Available online: http://www.smba.go.kr/eng/ polities/smepolicies_01.do?mc=usr0001170 (accessed on 11 October 2016). 
4. Jun, S.P.; Seo, J.H.; Son, J.K. A study of the SME Technology Roadmapping Program to strengthen the R\&D planning capability of Korean SMEs. Technol. Forecast. Soc. 2013, 80, 1002-1014.

5. Rumelt, R.P. Diversification strategy and profitability. Strateg. Manag. J. 1982, 3, 359-369. [CrossRef]

6. Porter, M.E. Competitive Strategy; The Free Press: New York, NY, USA, 1980.

7. Anıl, İ.; Yiğit, I. The relation between diversification strategy and organizational performance: A research on companies registered to the Istanbul stock exchange market. Proc. Soc. Behav. Sci. 2011, 24, 1494-1509. [CrossRef]

8. Chatterjee, S. Excess Resources, Utilization Costs, and Mode of Entry. Acad. Manag. J. 1990, 33, 780-800. [CrossRef]

9. Bettis, R.; Hall, W. Diversification strategy accounting determined risk, and accounting determined return. Acad. Manag. J. 1982, 45, 254-264. [CrossRef]

10. Craig, J.C.; Grant, R.M. Strategic Management; Kogan Page Limited: London, UK, 1993.

11. Koch, A.J. Selecting overseas markets and entry modes: Two decision processes or one? Mark. Intell. Plan. 2001, 19, 65-75. [CrossRef]

12. Cavusgil, S.T.; Kiyak, T.; Yeniyurt, S. Complementary approaches to preliminary foreign market opportunity assessment: Country clustering and country ranking. Ind. Market Manag. 2004, 33, 607-617. [CrossRef]

13. Douglas, S.P.; Lemaire, P.; Wind, Y. Selection of global markets: A decision-theoretic approach. In Proceedings of the XXII Esomar Congress, Esomar, France, 10-14 September 1972; pp. 237-251.

14. Root, F.R. Entry Strategies for International Markets; Lexington Books: Lexington, MA, USA, 1972.

15. Johanson, J. Global Marketing, Foreign Entry, Local Marketing and Global Management; McGraw-Hill: Chicago, IL, USA, 1997.

16. Merrifield, B. How to select successful R\&D projects. Manag. Rev. 1978, 67, 25-39.

17. Development of Identifying New Promising Items for the SMEs. Available online: http://report.ndsl.kr/ repDetail.do?cn=TRKO201500002309 (accessed on 25 October 2016).

(C) 2016 by the authors; licensee MDPI, Basel, Switzerland. This article is an open access article distributed under the terms and conditions of the Creative Commons Attribution (CC-BY) license (http://creativecommons.org/licenses/by/4.0/). 